\title{
Oxidative Stress Mediated Cytotoxicity of Trichloroethane in a Model of Murine Splenic Injury
}

\author{
Massaud S. Maamar ${ }^{1}$, Mohamed A. Al-Griw ${ }^{1}$, , Rabia O. Al-Ghazeer ${ }^{2}$, Seham A. Al-Azreg ${ }^{3}$, \\ Naser M. Salama ${ }^{1}$, Emad M. Bennour $^{4}$ \\ ${ }^{1}$ Division of Developmental Biology, Zoology Department, Faculty of Science, University of Tripoli, Tripoli, Libya \\ ${ }^{2}$ Chemistry Department, Faculty of Science, University of Tripoli, Tripoli, Libya \\ ${ }^{3}$ Department of Pathology and Clinical Pathology, Faculty of Veterinary Medicine, University of Tripoli, Tripoli, Libya \\ ${ }^{4}$ Department of Internal Medicine, Faculty of Veterinary Medicine, University of Tripoli, Tripoli, Libya
}

\section{Email address}

m.algriw@uot.edu.ly (M. A. Al-Griw)

${ }^{*}$ Corresponding author

\section{To cite this article:}

Massaud S. Maamar, Mohamed A. Al-Griw, Rabia O. Al-Ghazeer, Seham A. Al-Azreg, Naser M. Salama, Emad M. Bennour. Oxidative Stress Mediated Cytotoxicity of Trichloroethane in a Model of Murine Splenic Injury. American Journal of BioScience. Vol. 4, No. 1, 2016, pp. 1-8. doi: 10.11648/j.ajbio.20160401.11

Received: February 22, 2016; Accepted: March 1, 2016; Published: March 19, 2016

\begin{abstract}
The present in vivo murine study was aimed to investigate the long-term effect of repeated administration of low-dose of the environmental toxicant trichloroethane (TCE) over three weeks on the spleen and peripheral blood cells, and the possible role of oxidative stress in TCE-induced toxicity. The results showed neither adverse clinical signs nor mortality on the TCE-treated mice. However, significant changes were noticed in the spleen of those animals. Grossly, the spleen of TCE-treated group was congested and enlarged (splenomegaly). Histpathologically, the splenic tissues of TCE-treated mice showed signs of toxicity as highly activated germinal centers of the white pulp with minimal apoptotic reaction as well as a prominent megakarocytosis and infiltration of the red pulp by comparatively increased number of eosinophiIs and mature lymphocytes were detected. In addition, lymphocyte numbers were decreased in peripheral blood as well as basophils. In contrast, there was an increase in monocyte numbers in the peripheral circulation. In addition, lipid peroxidation/ malondialdehyde formation, a biomarker of oxidative stress, was significantly induced by TCE treatment in the sera and spleen of mice, suggesting an overall increase in oxidative stress. These results provide further support to a role of oxidative stress in TCE-induced cell death, which could result in an impaired spleen function. This study concludes that attenuation of TCE-induced splenic damage in mice provides an approach for preventive and/or therapeutic strategies.
\end{abstract}

Keywords: Environmental Toxicant, Spleen, Toxicity, Oxidative Stress, DNA Damage, Apoptosis, Mice

\section{Introduction}

In recent years, the extensive use of chemicals has been criticized due to their persistence in the environment and their accumulation in the living tissues of organisms. Evaluating the toxicity of chemicals, such as cadmium, mercury, bisphenol A (BPA), dioxin, and trichloroethane (TCE), is one of the most concerned issues in the modern society. Some of these toxicants show immediate impact while others can result in subtle alterations that are delayed in their expression [1]. TCE, an ubiquitous environmental toxicant, is a volatile organic solvent that has been used in large quantities as a dissolvent, metal degreaser, chemical intermediate, and component of consumer products [1-2]. Originally produced as a safer alternative to other chlorinated solvents, the TCE's acute and chronic toxicities are relatively low. However, there is a risk of toxic impacts to those that encounter TCE in high concentrations in the workplace or recreationally abuse the solvent [2-3]. It has been reported that severe exposures of humans to TCE have resulted in sensitization of the heart to epinephrine-induced arrhythmias and mild hepatorenal impacts [3], but the central nervous system (CNS) is considered the principal target. Acute exposures to volunteers have produced impaired 
performance in tests of manual dexterity, eye hand coordination, perceptual speed, and reaction time $[2,4]$. The spleen contains vascular and lymphoid elements and is a site of hematopoiesis and removal of affected, degenerated and aged red blood cells as well as particulate materials and circulating bacteria from the blood supply [5]. The spleen is a site of direct and indirect toxicity, a target for some carcinogens and also a site for metastasis of malignant neoplasms arising in other sites [5].

Spleen function can be affected through several cellular and molecular mechanisms. Numerous studies have suggested oxidative alterations in splenocytes such as mitochondrial dysfunction, membrane injury, and denaturation of DNA and other cell components [6]. Reactive oxygen species (ROS) formation, such as the superoxide anion $\mathrm{O}_{2}^{-}$and hydroxyl radicals $\left(\mathrm{HO}^{-}\right)$can lead to altered in the enzyme activity, decreased DNA repair, impaired utilization of oxygen, glutathione depletion, and lipid peroxidation. Some of these alterations induced by oxidative stress have been recognized to be characteristic features of necrosis [7-8]. Furthermore, pathological studies have involved the oxidative stress as a cause of cell death [6]. ROS have been involved in the pathogenesis of autoimmune diseases via dysregulation of immune function, autoantigen production through oxidative modification and induction of autoantibody formation [9-10]. A variety of ROS-mediated modifications of proteins have been reported in various diseases $[1,11]$. Increasing evidence suggests that those ROS-modified proteins, such as carbonyls and lipid peroxidation-derived aldehydes (LPDA), including malondialdehyde (MDA) and 4-hydroxynonenal (HNE)-protein adducts, may elicit an autoimmune response and contribute to disease pathogenesis [12]. Indeed, higher levels of MDA-/HNE-modified proteins and protein carbonyls have been seen in autoimmune disease patients [12-13], illustrating a role for these oxidatively modified proteins in autoimmune diseases. Oxidative stress can affect cell integrity only when antioxidant mechanisms are no longer able to cope with free radical generation.

To the best of our knowledge, until now there are few studies investigating the impact of TCE exposure on splenic tissues. Therefore, the main aim of this study was to investigate the long-term impact of low-dose exposure to TCE on the splenic tissues and the peripheral blood components in mice.

\section{Materials and Methods}

\subsection{Animals and Housing}

A total of twenty four female Albino mice aged between 4-6 weeks with a weight range of 21-24 g, were used in this study. Mice were kept under a constant light-dark cycle (dark period from 7: $00 \mathrm{pm}$ to 7: $00 \mathrm{am}$ ) at $24 \pm 1^{\circ} \mathrm{C}$ and $55 \pm 5 \%$ relative humidity. Food and drinking water were available ad libitum. All efforts were made to minimize the pain during animal handling and experimentation and to reduce the number of animals used. Animals were bred and experimentation was carried out in the animal house of Zoology Department at Faculty of Science, University of Tripoli, Libya.

\subsection{Experimental Design}

Animals were divided into four groups of six mice each. These groups were: $100 \mu \mathrm{g} / \mathrm{kg}$ TCE-treated group, $400 \mu \mathrm{g} / \mathrm{kg}$ TCE-treated group, sham control group, and vehicle control group. TCE (Baxter International) was dissolved in corn oil and administered to mice intraperitoneally with repeated doses of either 100 or $400 \mu \mathrm{g} / \mathrm{kg}$ (twice weekly for three weeks). The doses were calculated according to the mice body weight and delivered in $80-100 \mu 1$ of corn oil $[1,14]$. TCE doses were selected as they considered safe by Environmental Protection Agency (EPA) [15]. Mice serving as vehicle received corn oil only, while the sham control group has not received any treatment.

\subsection{Clinical Assessment}

During the course of the exposure period, mice were observed for any abnormal clinical signs or behavior that may result from toxicity. Mice were assessed for morbidity and mortality twice a day, at midmorning and late afternoon. Night deaths were to be recorded the next morning and two independent observers were available to confirm the cause of death to exclude TCE-nonrelated mortality.

\subsection{Tissue Processing and Histopathology}

The spleens were firstly immediately preserved in $10 \%$ formalin following their removal at necropsy for one hour to reverse the shrinkage that had been caused by the high concentration of formalin. Histological slides were prepared as previously standardized in our laboratory and described by [16]. The splenic tissues were dehydrated in an ascending grade of isopropyl alcohol by overnight immersion in $80 \%$ and $100 \%$ isopropyl alcohol for one hour. The dehydrated tissues were cleared in two changes of xylene for one hour each. The wax-impregnated tissues were embedded in paraffin blocks using wax of the same grade. The paraffin blocks were mounted and cut with a rotary microtome at a three-micron thickness. The sections were floated in a tissue floatation bath at $40^{\circ} \mathrm{C}$ and placed on glass slides that were smeared with equal parts of egg albumin and glycerol. The sections were then melted in an incubator at $60^{\circ} \mathrm{C}$ for five minutes and allowed to cool. Then, the sections were deparaffinized by immersion in xylene for ten minutes in a horizontal staining jar. The deparaffinized sections were washed in $100 \%$ isopropyl alcohol and stained in Ehrlich's hematoxylin for eight minutes in a horizontal staining jar. After staining with hematoxylin, the sections were washed in tap water and dipped in acid alcohol $(8.3 \% \mathrm{HCl}$ in $70 \%$ alcohol $)$ to remove the excess stain. The sections were then placed in running tap water for 10 minutes to promote bluing (slow alkalization). Then, the sections were counter-stained in $1 \%$ aqueous eosin $(1 \mathrm{~g}$ in $100 \mathrm{ml}$ tap water) for one minute, and the excess stain was washed in tap water before the sections were dried. The complete dehydration of the stained sections was achieved by 
placing them in an incubator at $60^{\circ} \mathrm{C}$ for five minutes. When the sections were cooled, they were mounted in DPX mount, which has the optical index of glass; the sections were wetted in xylene and inverted onto the mount and then placed on the cover slip for microscopic examination.

The spleen architecture was observed and imaged using a low-power objective under a light microscope (Leica, Germany). All histological assessments were investigated in a blinded fashion by two investigators.

\subsection{Peripheral Blood Sampling}

After three weeks of TCE treatment, the control and treated animals were euthanized under anesthesia (Nembutal, Sodium Pentobarbital, Sigma), and blood was withdrawn from the inferior vena cava. Sera from mice, obtained following blood clotting and centrifugation, were stored in small aliquots at $20^{\circ} \mathrm{C}$ until further analysis.

\subsection{Peripheral Blood Leukocyte Count}

Leukocytes (white blood cells; WBCs) were counted as previously described [17] on a blood film from control and TCE-treated mice. The blood film was left to dry in air for 5 minutes. The blood film was stained by covering the dry blood film with drops of Giemsa stain for 15 minutes. The slides were washed several times with tap water and then the blood film was dried in air. The slides were mounted with Canada balsam. Differential leukocytic count was performed under the high power of the microscope (Leica, Germany) field by field.

\subsection{Lipid Peroxidation (MDA) Measurment}

Lipid peroxidation level was determined spectrophotometrically as a concentration of final lipid peroxidation products, which in reaction with thiobarbituric acid (TBA) form colour complex (thiobarbituric acid-reactive substances, TBARS)

\subsubsection{Estimation of TBARS in Spleen Homogenate}

The supernatant of spleen homogenate $(10 \% \mathrm{~W} / \mathrm{V}$ in Phosphate buffered saline) $(1.0 \mathrm{ml})$ was added to $2 \mathrm{ml}$ of (1: 1 : 1 ratio) TCA-TBA HCL reagent (thioarbituric acid $0.37 \%$, $0.24 \mathrm{~N} \mathrm{HCL}$ and $15 \% \mathrm{TCA}$ ) and then boiled at $100^{\circ} \mathrm{C}$ for 15 minutes, and allowed to cool. After centrifugation at $3000 \mathrm{rpm}$ for 10 minutes, the supernatant was removed and the absorbance was read at $532 \mathrm{~nm}$. The calibration curve was obtained using different concentrations of 1, 1, 3, 3-tetramethoxypropane as standard to determine the concentration of TBA-MDA adducts in samples as $\mathrm{nmol} / \mathrm{ml}$ [18].

\subsubsection{Estimation of TBARS in the Sera}

$0.5 \mathrm{ml}$ of the sample was mixed with $2.5 \mathrm{ml}$ of TCA $20 \%$ $(\mathrm{m} / \mathrm{V})$ in order to precipitate the serum proteins and then the mixture was centrifuged at $1500 \times g$ for $10 \mathrm{~min}$. After that, 2 $\mathrm{ml}$ TBA $(0.2 \%)$ and $2.5 \mathrm{ml}$ of sulfuric acid $(0.05 \mathrm{M})$ was added to the sediment, shaken, and incubated for $30 \mathrm{~min}$ in a boiling water bath. Then, $4 \mathrm{ml} \mathrm{n}$-butanol was added, and the solution was centrifuged, cooled and the absorption of supernatant was obtained using spectrophotometer at $532 \mathrm{~nm}$. The calibration curve was obtained using different concentrations of 1, 1, 3, 3-tetramethoxypropane as standard to determine the concentration of TBARS in samples as $\mathrm{nmol} / \mathrm{ml}$ [18-19].

\subsection{Statistics}

Statistical significance was determined using analysis of variance or t-test, as appropriate (SPSS, version 20). Data are presented as means \pm SEM.

\section{Results}

\subsection{TCE Has not Induced an Acute Fatal Toxicity}

By the daily clinical follow-up of the mice in this study, no mortality has been recorded among mice in all groups along the course of the experiment, except for one death case belonged to $400 \mu \mathrm{g} / \mathrm{kg}$ TCE-treated group recorded four weeks post-treatment, and no signs of acute toxicity have been noticed.

\subsection{TCE Induced a Splenomegaly and Increased Numbers of Infiltrating Lymphocytes and Apoptotic Events in Splenic Tissues}

To investigate whether the early exposure to low-dose of TCE affects the spleen, the later of all mice in the different groups has been examined grossly and histpathologically.

\subsubsection{Gross Pathology}

At necropsy, no gross pathological changes have been noticed on control groups. However, a congested and enlarged spleen (splenomegaly) was seen in several TCE-treated mice (Figure 1). Sections from different parts of spleens were submitted to histopathological examination.
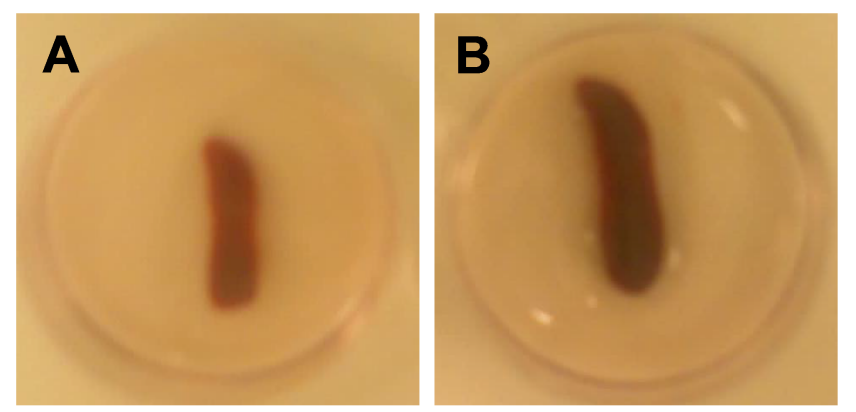

Figure 1. Representative pictures of gross appearance of spleen. A. Spleen of control mice with normal size and bright color. B. Congested and enlarged spleen (splenomegaly) of TCE-treated mice.

\subsubsection{Histopathological Changes of Splenic Tissues}

Histopathological examination showed that there was no histopathological changes in the spleen of sham controls (Figure 2); the spleens of control animals showed normal morphologic white and red pulp structures except for some apoptotic lymphocytes (pyknotic lymphocytes) in the germinal centers and mildly activated megakaryocytes 
represented in increased numbers and the presence of primitive cells. The red pulp was infiltrated by mature lymphocytes and a few eosinophiles. The results also showed there is a mild apoptotic changes (Figure 2, A and B).

The histopathological examination of splenic tissues of 100 $\mu \mathrm{g} / \mathrm{kg}$ TCE-treated mice showed moderate megakaryocytosis and infiltration of the red pulp by moderate number of mature lymphocytes and eosinophiles (Figure 2C). There were also mild apoptotic changes in the germinal centers of the white pulp. In addition, the walls of the central arterioles were ruptured and showed increasingly narrow lumens.

The histopathological changes caused by TCE treatment were remarkably increased in mice treated with $400 \mu \mathrm{g} / \mathrm{kg}$ of TCE (Figure 2D) as highly activated germinal centers of the white pulp with minimal apoptotic reaction as well as a prominent megakarocytosis and infiltration of the red pulp by comparatively increased number of eosinophiles and mature lymphocytes were detected (Figure 2D). Furthermore, a histocytosis represented by a focal replacement of the red pulp, and parts of the white pulp, by increased number of macrophages was seen. Multi-focal hemorrhages were also detected in the red pulp (Figure 2D).
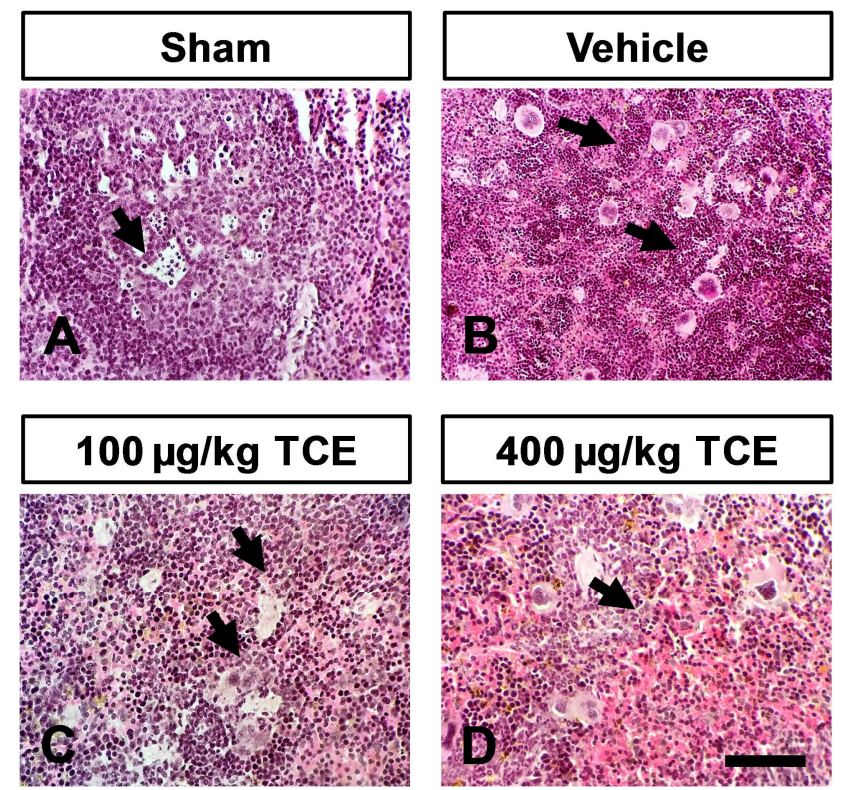

Figure 2. Representative splenic sections of control and TCE-treated mice (H\&E staining). A. A normal morphologic tissue architecture of white and red pulp with minimal apoptotic changes in some of the lymphocytes of germinal center in a sham control (100X). Apoptotic changes in some lymphocytes of the germinal center of the white pulp of a sham control (arrows). B. Activated germinal center with prominent mantile and peripheral zone cells ( $T$ lymphocytes) in a vehicle control (arrows) (100X). A moderate megakarocytosis and infiltration of moderate number of mature lymphocytes and few eosinophiles in the red pulp of a vehicle control (arrows). C. Splenic tissues of a $100 \mu \mathrm{g} / \mathrm{kg}$ TCE-treated mouse showing highly activated germinal center of the white pulp with minimal apoptotic reaction (arrows) (100X). An infiltration of the red pulp by moderate number of mature lymphocytes and eosinophiles in a $100 \mu \mathrm{g} / \mathrm{kg}$ TCE-treated mouse (arrows) (100X). D. Splenic tissues of a $400 \mu \mathrm{g} / \mathrm{kg}$ TCE-treated mice showing focal hemorrhage (arrows) (100X). Congestion, prominent megakarocytosis and infiltration of the red pulp by a comparatively increased number of eosinophiles and mature lymphocytes in a $400 \mu \mathrm{g} / \mathrm{kg}$ TCE-treated mice (arrows).

\subsection{The Impact of TCE on Peripheral Blood Cellular Components}

Further investigation of the impact of TCE was involved the cellular components of the peripheral blood through a differential cell count. The results have revealed a non-significant decrease in the total leukocyte (WBC) counts in $100 \mu \mathrm{g} / \mathrm{kg}$ TCE-treated mice $(39.44 \pm 2.79)$ compared to control $(P=0.416 ; 47.67 \pm 8.09$; Figure 3A). However, such a decrease was significant for the $400 \mu \mathrm{g} / \mathrm{kg}$ TCE-treated mice ( $P=0.015$ vs control; $22 \pm 4.16$; Figure $3 \mathrm{~A}$ ) comparing to controls.

Moreover, there was also a reduction in the counts of lymphocytes and basophils in the $100 \mu \mathrm{g} / \mathrm{kg}$ and $400 \mu \mathrm{g} / \mathrm{kg}$ TCE-treated groups compared to control (Figure $3 \mathrm{~B}$ and C). In contrast, the results showed a significant increase in the monocyte count in the $100 \mu \mathrm{g} / \mathrm{kg}$ and $400 \mu \mathrm{g} / \mathrm{kg}$ TCE-treated mice compared to control $(P<0.05$; Figure $3 \mathrm{~B}$ and $\mathrm{C})$. The quantitative analysis revealed that the percent of monocytes was higher in TCE-treated groups compared to controls. Although there were no significant differences $(\mathrm{P}>0.05)$ in the percent of monocytes between TCE-treated groups and controls, the percentage of monocyte increased by up to 1.16 -fold $(25.52 \pm 1.09 \%)$ and 1.17 -fold $(25.69 \pm 4.22 \%)$ in $100 \mu \mathrm{g} / \mathrm{kg}$ and $400 \mu \mathrm{g} / \mathrm{kg}$ TCE-treated mice respectively, compared to controls (21.93 $\pm 81 \%$; Figure 3D). Moreover, TCE treatment had no effect on the counts of neutrophils and eosinophiIs (data not shown).
A

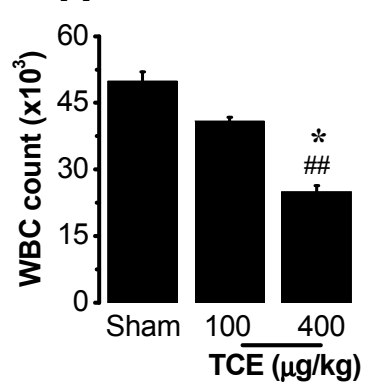

C

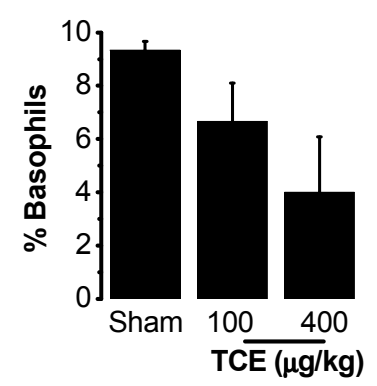

B

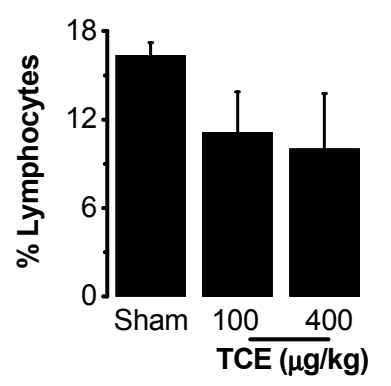

D

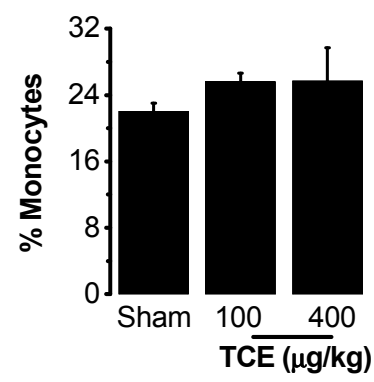

Figure 3. Changes in peripheral blood cellular counts due to repeated exposure to a low-dose of TCE over 3 weeks. A. Total leukocyte count in different mice groups. B. The parentage of lymphocyte in the peripheral blood film of different groups. $C$. The parentage of basophils in the peripheral blood film of different groups. D. The parentage of monocytes in the peripheral blood film of different groups. Values are appeared as means $\pm S E M$. \#*P< 0.05. \# vs controls; * vs $100 \mu \mathrm{g} / \mathrm{kg}$ TCE. 


\subsection{TCE Increases Lipid Peroxidation in the Serum}

TCE has been shown to generate free radicals and induce oxidative stress both in-vivo and in-vitro [1]. To evaluate the role of lipid peroxidation in TCE-induced toxicity, the serum levels of MDA in mice treated with TCE were determined (Figure 4). Lipid peroxidation (malondialdehyde; MDA) is a marker of oxidative lipid damage and a major oxidative product of peroxidized polyunsaturated fatty acids [19]. The results showed that serum MDA levels were significantly increased in the TCE-treated mice when compared with those in controls, with the highest levels recorded in the $400 \mu \mathrm{g} / \mathrm{kg}$ TCE-treated mice (Figure 4A). In addition, vehicle had no effect on the MDA levels when applied under normoxic condition (data not shown).

Since TCE-induced increases in MDA levels in the sera of TCE-treated mice, it was of interest to obtain further evidence for the involvement of oxidative lipid marker MDA in TCE-mediated splenic toxicity. Therefore, and due to the paucity of the biological material, the formation of MDA in the spleen homogenates of TCE-treated and controls mice in one experiment was also quantified. The results showed that TCE treatment led to a significant increase in the formation of MDA in the spleen of TCE-treated mice comparing to the controls (Figure 4B).
A

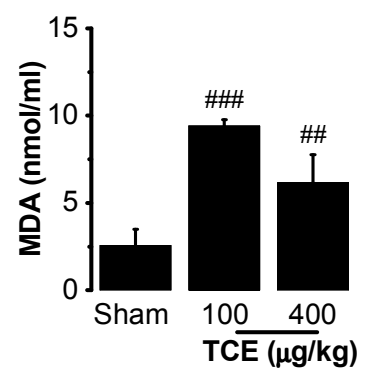

B

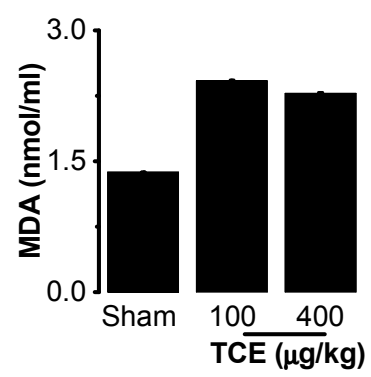

Figure 4. Changes of the levels of MDA due to TCE treatment. A. Levels of $M D A(\mathrm{nmol} / \mathrm{ml})$ in the sera of the different groups. B. Levels of MDA $(\mathrm{nmol} / \mathrm{ml})$ in the spleen homogenates of the different groups in a single experiment. The values are means $\pm S E M$. ${ }^{*} P<0.05$ vs. controls; $\# P<0.05$ vs. TCE-treated mice.

\section{Discussion}

It has been reported that the environmental chemical exposure can cause serious detrimental impacts on different biological systems [1, 20-26]. TCE is a non carcinogenic according to the last update of U. S Environmental Protection Agency (EPA) and the National Toxicology Program (NTP) technical reports [27-28], as there is no inadequate evidence for its carcinogenicity in both human and animal models. In addition, according to a WHO toxicological report, TCE is not considered as toxic compound [29]. However, the Agency for Toxic Substances and Disease Registry (ATSDR) indicated that TCE affects many internal organs within the cardiovascular and the nervous systems [30]. Despite the TCE safe profile claimed in the aforementioned reports, TCE toxicity was documented by several studies in many animal models [31-34]. Moreover, prior studies have reported that perinatal exposure to TCE affects the development of the brain, liver, adipose tissue and adversely affects their functions in animals [1, 21-25]. However, based on the best of the author's knowledge, no study had focused on the long-term impact of low-dose TCE exposure on the mouse spleen. Thus, this study was designed to explore the possible hazardous impacts of the exposure to environmentally relevant levels of TCE on splenic cytoarchitecture and peripheral blood cells at later life using a mouse model. The administration of TCE safe-considered doses to mice was through intraperitoneal injection. This mode of exposure has never been reported previously but the advantage of such exposure is to put the toxic chemical in close contact with the target cells and avoid rapid bio-elimination of TCE, which is two hours [35]. In-vivo experimental studies are crucial to evaluate environmental chemicals with adverse risk to health at birth or later in life. The in-vivo study of the toxicity of chemicals is of great importance because animal systems are extremely complicated, and the interaction of chemical compounds with biological components could lead to unique biodistribution, clearance, immune responses and metabolism.

In the present study, we showed that the early exposure to TCE can induce serious splenic toxicity and subsequent splenocyte death. The results also demonstrated that oxidative stress as a potential mechanism mediating splenocyte cell death. We sought to use a combination of techniques to obtain morphological and biochemical evidence for oxidative stress and apoptosis. Although other forms of cell death might have occurred, our data suggest that oxidative stress may contribute to the loss of splenocytes after TCE induced spleen injury.

The spleen contains hematopoietic and lymphoid elements, is a primary site of extramedullary hematopoiesis, removal of degenerated and aged red blood cells as well as particulate materials and circulating bacteria from the blood supply [5]. Lesions of this important component of the immune system may center on the red pulp, the white pulp or involve both compartments. The spleen is a site of direct and indirect toxicity, a target for some carcinogens, and also a site for metastatic neoplasia. Many systemic or generalized diseases have a splenic involvement [5]. Therefore, the pathological conditions interfering with the normal spleen physiology might result in impaired immune performance. Our data show that the spleens of mice treated with TCE showed many changes that may be due to the toxicity of TCE. Such changes included lymphocyte depletion in the white pulp associated with many aggregates of pyknotic cells. In addition, the walls of the central arterioles ruptured and showed increasingly narrow lumens. Major changes in the red pulp included increases in the numbers of macrophages, neutrophils and nests of pyknotic cells. The detection of pyknosis in the spleen may be related to an increase in $\mathrm{T}$ cell susceptibility to apoptosis, which may be an important mechanism of autoimmune diseases and immune senescence [36].

This study showed that TCE exposure could induce a splenomegaly, an enlargement in the spleen, highly likely due to an inflammatory process. Histpathologically, TCE exposure 
was associated with tissue changes in the spleens of mice treated with $100 \mu \mathrm{g} / \mathrm{kg}$ and $400 \mu \mathrm{g} / \mathrm{kg}$ of TCE which could be considered as a direct splenic toxicity due to TCE, as such changes have not been noticed in control mice. Similar spleen changes were previously reported [37], and all of these changes may be attributed to a loss of infiltration efficiency. The detection of pyknosis in the spleen may be related to an increase in T cell susceptibility to apoptosis, which may be an important mechanism of autoimmune diseases and immune senescence [36]. The TCE-treated mice had a significant increase in the number of apoptotic splenocytes while controls had only rare apoptotic cells. A limitation of this study is that the cell death mechanism/s triggered by TCE is/are not explored. A splenocyte cell death was viewed to occur by either apoptosis or necrosis following spleen injury [6]. Growing evidence from the increasing understanding of the biochemical and molecular mechanisms implicated in cell demise has provided an expanding view of various modes of cell death that can be triggered during both acute and chronic damage such as necroptosis, pyroptosis, and autophagic cell death [6]. However, the complexity of assessing the predominant mechanism of cell death during specific spleen damage in either humans or experimental in-vivo models is highlighted by the fact that, in many instances, there is significant crosstalk and overlap between the different cell death pathways [38].

Spleen function can be affected through several cellular and molecular mechanisms. Numerous studies have suggested oxidative alterations in splenocytes such as mitochondrial dysfunction, membrane injury, and denaturation of DNA and other cell components [6]. ROS formation, such as the superoxide anion $\mathrm{O}_{2}^{-}$and hydroxyl radicals $\left(\mathrm{HO}^{-}\right)$can lead to altered enzyme activity, decreased DNA repair, impaired utilization of oxygen, glutathione depletion, and lipid peroxidation. Some of these alterations induced by oxidative stress have been recognized to be characteristic features of necrosis [7-8]. Furthermore, pathological studies have involved the oxidative stress as a cause of cell death [6]. ROSs have been involved in the pathogenesis of autoimmune diseases via dysregulation of immune function, autoantigen production through oxidative modification and induction of autoantibody formation [9-10]. A variety of ROS-mediated modifications of proteins have been reported in various diseases [1, 11]. Increasing evidence suggests that those ROS-modified proteins such as protein carbonyls and lipid peroxidation-derived aldehydes [LPDAs, including malondialdehyde (MDA) and 4-hydroxynonenal (HNE)]-protein adducts may elicit an autoimmune response and contribute to disease pathogenesis [12]. Indeed higher levels of MDA-/HNE-modified proteins and protein carbonyls have been seen in autoimmune disease patients [12-13], illustrating a role for these oxidatively modified proteins in autoimmune diseases. Oxidative stress can affect cell integrity only when antioxidant mechanisms are no longer able to cope with free radical generation.

To further support these findings and offer new mechanistic evidence for the role of oxidative stress in TCE-induced toxicity, we first examined the markers of oxidative stress in the sera of TCE-treated mice. TCE-treated mice showed a significant increase in the serum MDA level compared to untreated controls. TCE insult also led to an increased formation of MDA in spleen cells, where TCE could generate free radicals and induce autoimmune disorders [1, 23]. The kinetics of the immune responses is largely orchestrated by the cellular peripheral blood components. The first and often most important response to infectious agents is non-specific immunity. This includes the soluble and cellular factors of acute inflammation, various serum proteins such as complement proteins and circulating and tissue phagocytes [39]. The primary function of leukocytes is defense against foreign bodies, which is achieved by leukocytosis and antibody production.

In this study, we found that the total WBC count was reduced in the peripheral blood of TCE-treated mice which could be attributed to their recruitment in the extra-vascular ongoing inflammatory reaction. This observation was not consistent with previous study [40]. In current study, we have also found that TCE treatment has induced an increase in monocyte counts in the peripheral circulation. However, such increase could be due to the escape of another cell component like lymphocytes from the circulation as a response to an extra-vascular inflammatory process.

In conclusion, the current study indicates that early exposure to low-dose of TCE could cause a serious damage to the mouse spleen and changes of relative counts of peripheral blood cells. Further studies focused on the potential pathways mediating splenocyte death and the effect of such damage on the number and the characteristics of circulating cells in the peripheral blood circulation should be performed in order to determine the mechanism(s) by which TCE inducing splenic toxicity/ damage and its biological consequences.

\section{Acknowledgement}

This investigation was supported in part by the Division of Developmental Biology, Faculty of Science, University of Tripoli, Libya. The authors should like to thank Turkia Aduma, the technical staff at the Department of Pathology and Clinical Pathology, Faculty of Veterinary Medicine, University of Tripoli, Libya, for her technical assistance.

\section{References}

[1] Wang, G., Wang, J., Ma, H., Ansari, G. A. S., and Khan, M. F. (2013) N-Acetylcysteine protects against trichloroethene-mediated autoimmunity by attenuating oxidative stress, Toxicology and Applied Pharmacology 273, 189-195.

[2] Warren, D. A., Reigle, T. G., Muralidhara, S., and Dallas, C. (1998) Schedule-controlled operant behavior of rats during 1,1,1-trichloroethane inhalation: relationship to blood and brain solvent concentrations, Neurotoxicol Teratology 20, 143-153. 
[3] ATSDR:- Toxicological Profile for 1,1,1-trichloroethane (update). U. S. Department of Health and Human Services, Public Health Service. August 1995.

[4] Mackay, C. J., Campbell, L., Samuel, A. M. (1987) Behavioral changes during exposure to 1,1,1-trichloroethane: time-course and relationship to blood solvent levels, American Journal Ind Medicine 11, 223-239.

[5] Suttie, A. W. (2006) Histopathology of the Spleen, Toxicologic Pathology 34, 466-503.

[6] Li, J. L., Li, H. X., Li, S., Tang, Z. X., Xu, S. W., Wang, X. L. (2010) Oxidative Stress-Mediated Cytotoxicity of Cadmium in Chicken Splenic Lymphocytes, Polish J. of Environ. Stud. 19, 947-956.

[7] Gujral, J. S., Bucci, T. J., Farhood, A., and Jaeschke, H. (2001) Mechanism of Cell Death During Warm Hepatic Ischemia-Reperfusion in Rats: Apoptosis or Necrosis?, Histology 33, 397-405.

[8] Gujral, J. S., Knight, T. R., Farhood, A., Bajt, M. L., and Jaeschke, H. (2002) Mode of cell death after acetaminophen overdose in mice: apoptosis or oncotic necrosis?, Toxicological Sciences 67, 322-328.

[9] Khan, M. F., Wu, X., and Ansari, G. A. (2001) Anti-malondialdehyde antibodies inMRL $+/+$ mice treatedwith trichloroethene and dichloroacetyl chloride: possible role of lipid peroxidation in autoimmunity, Toxicology Applied Pharmacology 170, 88-92.

[10] Oates, J. C. (2010) The biology of reactive intermediates in systemic lupus erythematosus, Autoimmunity 43, 56-63.

[11] Morgan, P. E., Sturgess, A. D., Davies, M. J. (2005) Increased levels of serum protein oxidation and correlation with disease activity in systemic lupus erythematosus, Arthritis Rheum 52, 2069-2079.

[12] Ben Mansour, R., Lassoued, S., Elgaied, A., Haddouk, S., Marzouk, S., Bahloul, Z., Masmoudi, H., Attia, H., Aïfa, M. S., Fakhfakh, F. (2010) Enhanced reactivity to malondialdehydemodified proteins by systemic lupus erythematosus autoantibodies, Scand. J. Rheumatol 39, 247-253.

[13] Wang, G., Pierangeli, S. S., Papalardo, E., Ansari, G. A., Khan, M. F. (2010) Markers of oxidative and nitrosative stress in systemic lupus erythematosus: correlation with disease activity, Arthritis Rheum 62, 2064-2072.

[14] Melani, A., Pantoni, L., and Bordoni, F. (2003) The selective A2A receptor antagonist SCH 58261 reduces striatal transmitter outflow, turning behavior and ischemic brain damage induced by permanent focal ischemia in the rat, Brain Research 959, 243-250.

[15] Lane, R. W., Riddle, B. L.; Borzelleca, J. F. (1982) Effects of 1,2-dichloroethane and 1,1,1-trichloroethane in drinking water on reproduction and development in mice., Toxicol Appl Pharmacology 63, 409-421.

[16] Schalm, O. W., Jaim, N. C., and Carroll, E. J. (1975) Veterinary Haematology. 3rd (ed.) Lea. And Febiger, Philadelphia, U. S. A.

[17] Burtis, C. A., Ashwood, E. R. (1999) Tietz Textbook of Clinical Biochemistry, 3rd. Ed., WB. Saunders Co, Tokyo. p.1034-54.
[18] Zhang, Y. T., Zheng, Q. S., Pan, J., Zheng, R. L. (2004) Oxidative damage of biomolecules in mouse liver induced by morphine and protected by antioxidants, Basic Clin. Pharmacol. Toxicol. 95, 53-58.

[19] Al-Griw, M. A., Salama, N. M., Treesh, S. A., Elnfati, A. H. (2015) Transgenerational Genetic Effect of Trichloroethane (TCE) on Phenotypic Variation of Acrosomal Proteolytic Enzyme and Male Infertility Risk, International Journal of Genetics and Genomics 3, 43-49.

[20] House, R. A., Liss, G. M., Wills, M. C., Holness, D. L. (1996) Paresthesias and sensory neuropathy due to 1,1,1-trichloroethane, Journal occupational environmental Medicine 38, 123-124.

[21] Topham, J. C. (1980) Do induced sperm-head abnormalities in mice specifically identify mammalian mutagens rather than carcinogens, Mutat Res 74, 379-387.

[22] Griffin, J. M., Blossom, S. J., Jackson, S. K., Gilbert, K. M., Pumford, N. R. (2000) Trichloroethylene accelerates an autoimmune response by Th1 $\mathrm{T}$ cell activation in $\mathrm{MRL}+/+$ mice, Immunopharmacology 46, 123-137.

[23] Wang, G., Cai, P., Ansari, G. A. S., and Khan, M. F. (2007) Oxidative and nitrosative stress in trichloroethene-mediated autoimmune response, Toxicology 229, 186-193.

[24] Snyder, R., Andrews, L. S. (1996) Toxic effects of solvents and vapors. In: Klaassen, CD; ed. Casarett and Doull's Toxicology: The Basis Science of Poisons, 5th ed. New York: McGraw-Hill.

[25] Al-Griw, M. A., Salama, N. M., Treesh, S. A., Algadi, L. N., and Elnfati, A. H. (2015) Cell Death in Mouse Brain following Early Exposure to Trichloroethane (TCE), International Journal of Advanced Research 3, 1424-1430.

[26] NTP. (2000) NTP technical report on the toxicity studies of 1,1,1-trichloroethane administered in microcapsules in feed to F344/N rats and B6C3F1 mice., National Toxicology Program. (41) NIH 004402.

[27] EPA. (2007) Toxicological Review of 1,1,1-Trichloroethane (CAS No. 71-55-6) In Support of Summary Information on the Integrated Risk Information System (IRIS)., EPA/635/R-03/013. U. S. Environmental Protection Agency, Washington, DC..

[28] WHO. (2003) 1,1,1-Trichloroethane in Drinking-water. Background document for development of

[29] WHO Guidelines for Drinking-water Quality., World Health Organization WHO/SDE/WSH/03.04/65., 16.

[30] ASTDR. (2006) 1,1,1 Trichloroethane, Agency for Toxic Substances and Disease Registry, 371.

[31] Quast, J. F., Calhoun, L. L., and Frauson, L. E. (1988) 1,1,1-trichloroethane formulation: a chronic inhalation toxicity and oncogenicity study in Fischer 344 rats and B6c3F1 mice, Fundam Appl Toxicol 11, 611-625.

[32] Tyson, C. A., Hawk-Prather, K., Story, D. L., and Gould, D. H. (1983) Correlations of in vitro and in vivo hepatotoxicity for five haloalkanes, Toxicol Appl Pharmacol 70, 289-302.

[33] Bruckner, J. V., Kyle, G. M., Luthra, R., Acosta, D., Mehta, S. M., Sethuraman, S., and Muralidhara, S. (2001) Acute, short-term, and subchronic oral toxicity of 1,1,1-trichloroethane in rats, Toxicol Sci 60, 363-372. 
[34] Kinkead, E., and Leahy, H. (1987) Evaluation of the acute toxicity of selected groundwater contaminants., Harry G. Armstrong Aerospace Medical Research Lab (AAMRL-TR-87-021), 10.

[35] Bogen, K., and Hall, L. ( 1989) Pharmacokinetics for regulatory risk analysis: The case of 1,1,1-trichloroethane (methyl chloroform)., Regul Toxicol Pharmacol 10, 26-50.

[36] Hsu, H. C., Mountz, J. D. (2003) Origin of late-onset autoimmune disease, Immunol. Allergy Clin. North. Am 23, 65-82.

[37] Balani, T., Agrawal, S., Thaker, A. M. (2008) Effects of imidacloprid a neonicotinoid insecticide on the immune system of white leghorn cockerels, Journal of Vet. Pharm. Toxicology 7, 27-30.

[38] Eguchi, A., Wree, A., Feldstein, A. E. (2014) Biomarkers of liver cell death, Journal of Hepatology 60, 1063-1074.

[39] Adedeji, O. B., Adeyemo, O. K., Agbede, S. A. (2009) Effects of diazinon on blood parameters in the African catfish (Clarias Gariepinus), Afr. J. Biotechnology 8, 3940-3946.

[40] Hobara, T., Kobayashi, S., Higashihara, E. (1983) Changes in hematologic parameters with acute exposure to 1 , 1, 1-trichloroethane, Ind Health 21, 255-261. 